\title{
Prenatal Exposure to Persistent Organic Pollutants and Anogenital Distance in Children at 18 Months
}

\author{
Miguel García-Villarino a, b Isolina Riaño-Galán ${ }^{\text {a, c }}$ \\ Ana Cristina Rodriguez-Dehlid ${ }^{d}$ Esther Vizcaíno ${ }^{\mathrm{e}}$ Joan O. Grimalt ${ }^{\mathrm{e}}$ \\ Adonina Tardón ${ }^{\mathrm{a}, \mathrm{b}}$ Ana Fernández-Somoano ${ }^{\mathrm{a}, \mathrm{b}}$ \\ a Spanish Consortium for Research on Epidemiology and Public Health (CIBERESP), Madrid, Spain; \\ b Unit of Molecular Cancer Epidemiology, University Institute of Oncology of the Principality of Asturias (IUOPA), \\ Department of Medicine, University of Oviedo, Oviedo, Spain; ' $P$ Pediatric Endocrinology, HUCA, Oviedo, Spain; \\ dPediatric Endocrinology, San Agustín Hospital, Avilés, Spain; 'Department of Environmental Chemistry, \\ Institute of Environmental Assessment and Water Research (ID/EA-CSIC), Barcelona, Spain
}

\section{Keywords}

Anogenital distance - Persistent organic pollutants · Endocrine disruption - Environmental contaminants · Children

\begin{abstract}
Background: Anogenital distance (AGD) is a measure of in utero exposure to hormonally active agents. The aim of the present study was to evaluate the association between prenatal exposure to persistent organic pollutants (POPs) and AGD. Methods: POP levels were measured in pregnant women, and the AGD was recorded in 43 offspring at 18 months. We used linear regression models to analyze the association between maternal POP exposure and offspring AGD. We defined the anogenital index (AGI) as AGD divided by weight at 18 months (AGI = AGD / weight at 18 months $[\mathrm{mm} / \mathrm{kg}]$ ) and included this variable in the regression models. Results: AGI measure was $2.35(0.61)$ and $1.38(0.45)$ in males and fe-
\end{abstract}

\begin{tabular}{ll}
\hline KARGER & ( 2018 The Author(s) Karger \\
& Published by S. Karger AG, Basel Open access \\
E-Mail karger@karger.com & This article is licensed under the Creative Commons Attribution- \\
www.karger.com/hrp & $\begin{array}{l}\text { NonCommercial-NoDerivatives 4.0 International License (CC BY- } \\
\text { NC-ND) (http://www.karger.com/Services/OpenAccessLicense). } \\
\text { Usage and distribution for commercial purposes as well as any dis- } \\
\text { tribution of modified material requires written permission. }\end{array}$
\end{tabular}

males, respectively. AGI was inversely associated with lipidadjusted concentrations of PBDE-99 ( $\beta=-0.28,95 \%$ confidence interval $[\mathrm{Cl}]:-0.51,-0.04)$ and PBDE-153 $(\beta=-0.61$, $95 \% \mathrm{Cl}:-1.11,-0.11)$ in males. We did not find any statistically significant relationship between any POPs and AGI in females. Conclusions: Environmental exposure to POPs may affect genital development and result in reproductive tract alterations with potentially relevant health consequences in maturity.

(C) 2018 The Author(s)

Published by S. Karger AG, Basel

\section{Introduction}

Intrauterine exposure to environmental pollutants such as persistent organic pollutants (POPs), including organochlorine compounds (OCs) or polybrominated diphenyl ethers (PBDEs), could increase the risk of adverse health effects in children, as the prenatal stage is 
important to development. OCs such as 4,4-dichlorodiphenyltrichloroethane (DDT), hexachlorocyclohexane, pentachlorobenzene, hexachlorobenzene, and polychlorinated biphenyls (PCBs) and organobromines such as PBDEs are toxic environmental pollutants that have been used extensively as pesticides or flame retardants [1]. These products were added to the list of POPs under the Stockholm Convention in 2009 [2]. Nowadays, their synthesis is severely restricted or banned, but they persist in the environment and in human tissues owing to their high lipophilicity and biomagnifying properties [3-5].

Anogenital distance (AGD) is an anthropometric parameter that has been validated as a sensitive marker of intrauterine exposure to androgens and antiandrogens $[6,7]$. According to the 1992 Princeton Consensus on sexual dysfunction and cardiac risk, an endocrinological disruptor (also known as an endocrine-disrupting chemical [EDC]) is defined as an exogenous substance or mixture that alters functions of the endocrine system and consequently causes adverse health effects in an intact organism or its progeny or subpopulations [8].

Optimal functioning of both feminine and masculine genitals requires a balance between androgens and estrogens. Female differentiation occurs largely independently of estrogens, whereas male sexual differentiation is androgen-dependent and potentially estrogen-dependent [9]. Therefore, estrogen excess causes a decrease in the steroidogenic activity of the enzymes responsible for converting progesterone to testosterone; estrogens have also been shown to contribute to reduced production of follicle-stimulating hormone in male fetuses and a decrease in Sertoli cells, resulting in a low sperm count $[10,11]$.

Endocrine-disrupting molecules are found in pesticides such as DDT or PCBs and in flame retardants containing phenol derivatives such as PBDEs. These chemicals contaminate water, soil, and food [12] and exert their effects by activating and modulating the estrogenic receptors located in the female and male gonads.

There is extensive medical literature supporting the association of environmental toxicant exposure and AGD decreases in animals [13-15]. Some studies have used AGD as a measure of fetal androgenic or antiandrogenic action. AGD has been found to relate to body weight in rodents, as both measures are independent endocrine effects. AGD generally corresponds to the androgenic load received throughout life and can predict other androgensensitive endpoints $[13,16]$. Exposure to estrogen compounds may have an inhibitory action on steroidogenesis contributing to the decrease of androgens levels and AGD [9].

Anogenital Distance and Exposure to

Endocrine Disruptors
The early exposure to POPs could constitute an environmental risk to human health due to implications in children's genital development and their possible androgenic/antiandrogenic or estrogenic effect. To date, some studies have evaluated the relationship between the environmental endocrine disruptors such as phthalates or DDT and the decrease of AGD [17-21]. To our knowledge, there are no published studies on the relationship between exposure to PBDEs and PCBs and AGD.

Intrauterine exposure to POPs may be a factor in decreased AGD among children. Thus, the aim of the present study was to evaluate the association between prenatal exposure to POPs and AGD. The work was undertaken within the INMA (INfancia y Medio Ambiente - Environment and Childhood) Project in Spain.

\section{Methods}

Study Design and Population

The INMA Project is a multicenter population-based motherchild cohort study established in different areas of Spain following a common protocol. The project analyzes the influence of prenatal environmental exposures on the growth, development, and health of infants from gestation to childhood [22]. The present study's cohort included pregnant women who agreed to participate in the INMA Asturias cohort and their newborns. Asturias is located in northern Spain on the Cantabrian coast. A total of 485 pregnant women were recruited at the reference Hospital San Agustín in Avilés (Asturias) between May 2004 and June 2007. Deliveries at the hospital occurred between October 2004 and February 2008. Pregnant women completed two detailed questionnaires on anthropometric and sociodemographic characteristics and lifestyle variables.

\section{Analytical Techniques}

Hospital staff collected maternal blood samples from 355 women during pregnancy. POP concentrations in 355 maternal blood samples were analyzed. Maternal blood was collected during the first trimester of gestation (median: 12 weeks; range: 10-13 weeks) by trained midwives following the INMA cohort protocol [22]. Aliquots of the samples were placed in Vacutainer blood collection tubes and stored away from light at $4{ }^{\circ} \mathrm{C}(1-2 \mathrm{~h}$ from collection) until centrifugation for $15 \mathrm{~min}$ at 2,500-3,000 rpm. The serum obtained was aliquoted into $2-\mathrm{mL}$ glass cryotubes and stored at $-80^{\circ} \mathrm{C}$. Samples collected were analyzed at the Barcelona Institute of Environmental Assessment and Water Research as previously described [1].

Limits of detection for OCs ranged from 0.010 to $0.035 \mathrm{ng} / \mathrm{mL}$. OC analysis was performed by gas chromatography with electron capture detection (Agilent Technologies $6890 \mathrm{~N}$, Santa Clara, CA, USA) using a DB- 5 column protected by a retention gap ( $60 \mathrm{~m} \times$ $0.25 \mathrm{~mm}$ I.D., 0.25- $\mu \mathrm{m}$ film thickness; J\&W Scientific, Folsom, CA, USA). The carrier gas was helium (constant flow $1.5 \mathrm{~mL} / \mathrm{min}$ ). Injection $(2 \mu \mathrm{L})$ was in splitless mode at $280^{\circ} \mathrm{C}$. Nitrogen $(60 \mathrm{~mL} /$ min) was the makeup gas. The electron capture detection was set at $310^{\circ} \mathrm{C}$. The temperature was held at $90^{\circ} \mathrm{C}$ for $2 \mathrm{~min}$, and then 
ramped to $130^{\circ} \mathrm{C} / \mathrm{min}$ and to $290^{\circ} \mathrm{C}$ at $4{ }^{\circ} \mathrm{C} / \mathrm{min}$, with a final holding time of $20 \mathrm{~min}$. The total run time was $60.67 \mathrm{~min}$. The laboratory methods and quality control procedures for the analysis of organohalogen compounds have been described elsewhere [23, 24]. PBDE congeners were analyzed by gas chromatography coupled to mass spectrometry in chemical ionization mode and negative ion recording.

Total cholesterol and triglycerides were determined in maternal serum samples using colorimetric enzymatic methods in the General Biochemistry Laboratory of Hospital San Agustín. The samples were processed using a Roche Diagnostics COBAS C711. Total serum lipid concentrations were calculated as described by Phillips et al. [25] using the following formula:

$$
{ }^{\text {oоo }} \mathrm{TL}^{1}{ }_{4} \text { ð2:27 TCP p TG p 62:3 mg } \times \mathrm{dL}^{-1} \text {. }
$$

\section{AGD Measurements}

We analyzed anoscrotal distance (anus to scrotum) and anofourchetal distance (anus to fourchette) in boys and girls, respectively, at 18 months. The technique for AGD measurement has been described in detail elsewhere [13]. Briefly, the newborn was in the dorsal decubitus position; both hips were flexed and light pressure was exerted on the infant's thighs. Measurements were made with Vernier calipers. Distance was measured from the center of the anus to the posterior convergence of the fourchette in female infants and to the junction of the smooth perineal skin of the scrotum in male infants. All AGD measurements were taken in the reference Hospital San Agustín in Avilés. We were able to measure the AGD in 44 children aged 18 months and stratified the measurements by sex. All measures were performed by two trained pediatricians.

\section{Other Variables}

We considered the following maternal characteristics: age (years), height $(\mathrm{cm})$, pre-pregnancy body mass index (BMI), and weight gain during pregnancy, in accordance with the recommendations of the Institute of Medicine [26]. We also considered the following characteristics of the newborn: birth weight $(\mathrm{g})$, birth length $(\mathrm{cm})$, weight at 18 months $(\mathrm{g})$, length at 18 months $(\mathrm{cm})$, and BMI at 18 months $\left(\mathrm{kg} / \mathrm{m}^{2}\right)$.

\section{Statistical Analysis}

Of the 44 infants for whom AGD was obtained at 18 months, we excluded 1 for incomplete data on prenatal exposure to POPs. The sample used for the analysis comprised the remaining 43 mother-infant pairs. All statistical analyses and plotting were performed using the $\mathrm{R}$ statistical software package [27]. $p$ values $<0.05$ were considered statistically significant. Outcomes were evaluated for normal distribution and outliers by sex. Birth weight, birth length, weight and length at 18 months, and BMI were within normal ranges in all children; therefore, the data did not require transformation. POP concentrations were logarithmically transformed to normalized distributions. We used the anogenital index (AGI = AGD / weight at 18 months $[\mathrm{mm} / \mathrm{kg}]$ ), as previously described by Swan et al. [17].

We used the crude values for comparisons between groups and to calculate Spearman correlation coefficients. Data were stratified by sex. We used linear regression models to assess the association between AGI and individual POPs. Both crude and adjusted values for height at 18 months, in males and females, were used.

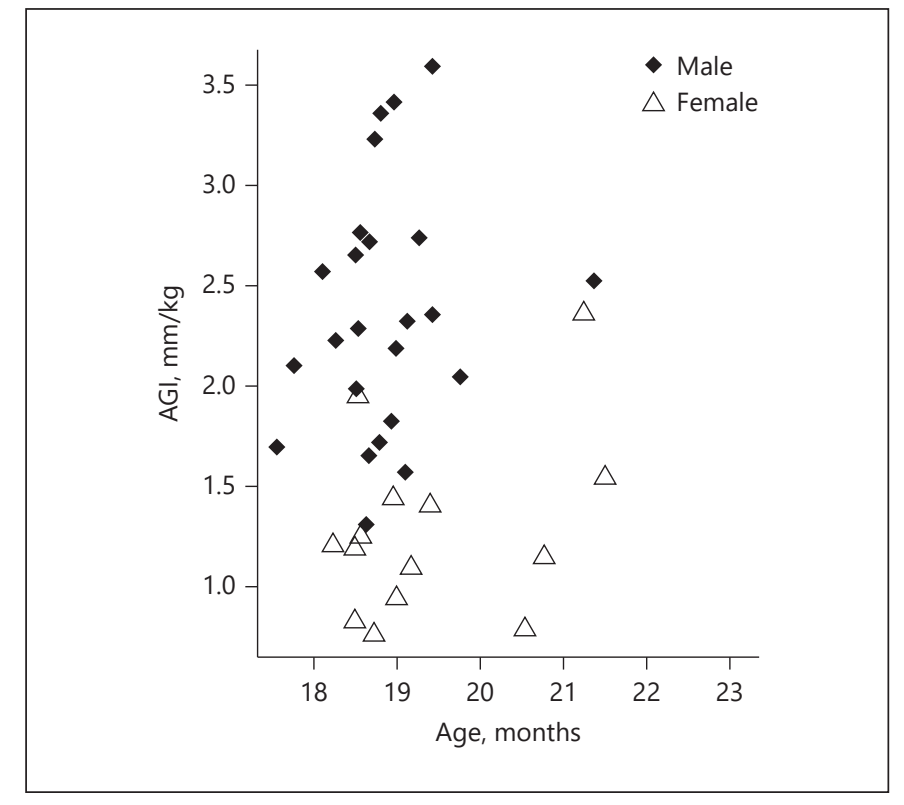

Fig. 1. AGI ( $\mathrm{mm} / \mathrm{kg})$ by children's age at examination.

\section{Results}

The median maternal age was 32 years (range: $23-41$ ), the median height was $161 \mathrm{~cm}$, and the median BMI was $23.2 \mathrm{~kg} / \mathrm{m}^{2}$. This distribution is homogeneous with the entire INMA Asturias cohort (data not shown). The mean weight and length of newborns at birth were $3.35 \mathrm{~kg}$ and $50 \mathrm{~cm}$, respectively.

Among the 43 infants, no genital malformations or disorders were detected, and no parameters appeared grossly abnormal in either sex. The AGD range was 17-41 $\mathrm{mm}$ in male infants, with a mean (SD) of $29.15(6.67) \mathrm{mm}$. In female infants, the AGD range was $10-41 \mathrm{~mm}$, with a mean (SD) of 17.31 (7.88) $\mathrm{mm}$.

The mean (SD) AGI value was $2.35(0.61) \mathrm{mm} / \mathrm{kg}$ in males and $1.38(0.45) \mathrm{mm} / \mathrm{kg}$ in females. Figure 1 shows the values of AGI by age in the sampled population, stratified by sex. The children's mean (SD) weight, height, and BMI at 18 months were 12.35 (1.59) kg, $82.93(3.41) \mathrm{cm}$, and 17.67 (1.67) kg/m², respectively (Table 1 ).

At 18 months, we analyzed the AGI measurements for correlation with measures of body size and with maternal characteristics. In males, AGI was correlated with BMI $(R h o=-0.61 ; p$ value $=0.004)$. In females, AGI was correlated with height at 18 months $(R h o=-0.52 ; p$ value $=$ 0.05) (Table 1). We also used a simple linear regression model to assess the association of each POP with AGI, 
Table 1. Characteristics of the population: the Asturias INMA cohort

\begin{tabular}{|c|c|c|c|c|c|c|c|c|c|c|c|}
\hline Physiological variables & $n$ & Mean \pm SD & Min. & P25 & Median & P75 & Max. & $\begin{array}{l}\text { Rho } \\
\text { Spearman } \\
\text { (female) }\end{array}$ & $\begin{array}{l}p \\
\text { value }\end{array}$ & $\begin{array}{l}\text { Rho } \\
\text { Spearman }{ }^{\mathrm{a}} \\
\text { (male) }\end{array}$ & $p$ value \\
\hline \multicolumn{12}{|l|}{ Infant } \\
\hline \multicolumn{12}{|l|}{ AGD at 18 months, $\mathrm{mm}$} \\
\hline Male & 27 & $29.15 \pm 6.67$ & 17 & 23.5 & 29 & 35 & 41 & - & - & - & - \\
\hline Female & 16 & $17.31 \pm 7.88$ & 10 & 13 & 14.5 & 18.5 & 41 & - & - & - & - \\
\hline \multicolumn{12}{|l|}{ AGI, mm/kg } \\
\hline Male & 25 & $2.35 \pm 0.61$ & 1.31 & 1.98 & 2.29 & 2.72 & 4 & - & - & - & - \\
\hline Female & 14 & $1.38 \pm 0.45$ & 0.76 & 0.98 & 1.2 & 1.43 & 2.36 & - & - & - & - \\
\hline Birth weight, g & 43 & $3.35 \pm 3.65$ & 2.72 & 3.07 & 3.31 & 3.61 & 4 & -0.691 & 0.060 & 0.109 & 0.600 \\
\hline Birth height, $\mathrm{cm}$ & 43 & $49.98 \pm 1.57$ & 47 & 49 & 50 & 51 & 54 & -0.303 & 0.290 & 0.257 & 0.213 \\
\hline Weight at 18 months, $g$ & 39 & $12.35 \pm 1.59$ & 9.67 & 11.21 & 12.2 & 13.45 & 16 & -0.468 & 0.090 & -0.358 & 0.078 \\
\hline Height at 18 months, $\mathrm{cm}$ & 35 & $82.93 \pm 3.41$ & 77 & 80.5 & 83 & 84.8 & 93 & -0.517 & 0.050 & -0.318 & 0.158 \\
\hline BMI at 18 months, $\mathrm{kg} / \mathrm{m}^{2}$ & 35 & $17.67 \pm 1.67$ & 12.9 & 16.5 & 17.5 & 18.7 & 20.8 & -0.287 & 0.317 & -0.606 & 0.004 \\
\hline \multicolumn{12}{|l|}{ Mother } \\
\hline Height, cm & 43 & $162.51 \pm 6.04$ & 150 & 160 & 161 & 166 & 175 & -0.245 & 0.398 & -0.239 & 0.342 \\
\hline $\mathrm{BMI}, \mathrm{kg} / \mathrm{m}^{2}$ & 43 & $24.39 \pm 5.1$ & 18.4 & 20.6 & 23.2 & 26.8 & 40.2 & -0.004 & 0.988 & 0.037 & 0.854 \\
\hline Age, years & 43 & $32.16 \pm 4.29$ & 23 & 29.5 & 32 & 35 & 41 & -0.337 & 0.230 & -0.049 & 0.815 \\
\hline
\end{tabular}

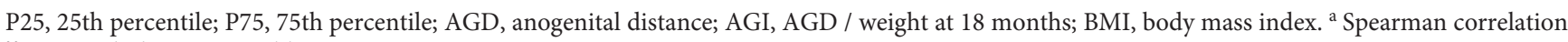
coefficient with the AGI variable.

stratified by sex. Table 2 shows the model's values; model 1: crude nonadjusted model, model 2: adjusted for height at 18 months. Male offspring AGI was inversely associated with maternal serum concentrations of PBDE-99 $(\beta=-0.28,95 \%$ confidence interval $[\mathrm{CI}]:-0.51,-0.04)$ and PBDE-153 ( $\beta=-0.61,95 \%$ CI: $-1.11,-0.11)$. In female offspring, we did not observe any statistically significant association between maternal serum of POPs and AGI (Table 2).

\section{Discussion}

We found a negative association between AGI at 18 months of age and prenatal exposure to PBDE-99 and PBDE-153 in males. Although these findings should be confirmed in larger samples, this research provides important epidemiological evidence that prenatal exposure to POPs might be associated with shortened AGD in offspring.

Prenatal androgen action can be quantified using the AGD as a biomarker of the antiandrogenic effects of EDCs in humans. The external genitalia are sexually dimorphic at birth. Various protocols have been used to measure AGD. We selected the protocol developed by Salazar-Martinez et al. [13] because that group was the first to study the AGD in both sexes (measured from the center of the anus to the base of the scrotum in males and from the center of the anus to the posterior fourchette in females) $[28,29]$. Cryptorchidism and hypospadias are less-reliable markers of endocrine disruption than the AGD [30]. It may therefore be a useful tool in population studies on the effects of POPs.

In our study, the mean AGD value in males at 18 months $(29.15 \mathrm{~mm})$ was $8.15-10.05 \mathrm{~mm}$ higher than the measures published in 3 previous studies carried out in Mexican newborns [13, 20, 29]. However, when we compared the mean (SD) AGI index, we found that our index was 2.35 ( \pm 0.61 ), i.e., $2-3$ times less than the data reported by Swan et al. [17] (7.4 mm/kg), Huang et al. [19] (7.16 $\mathrm{mm} / \mathrm{kg})$, or Torres-Sanchez et al. [21] $(6.0 \mathrm{~mm} / \mathrm{kg})$.

In females, the mean value of the AGD at 18 months $(17.31 \mathrm{~mm})$ was similar to the one reported by Phillip et al. [31] $(16.1 \mathrm{~mm})$ in an Israeli population, but was 6.41 $\mathrm{mm}$ higher than the mean values recorded by Callegari et al. [32] in the US, and $7.31 \mathrm{~mm}$ higher than values reported by Salazar-Martinez et al. [13]. The mean AGI $(1.38 \mathrm{~mm} / \mathrm{kg})$ was also lower than the AGI reported by Huang et al. [19] $(5.37 \mathrm{~mm} / \mathrm{kg})$. These differences could be attributable to measurements taken at different ages; in this aspect it would be interesting to standardize the measurement (through the AGI for example) so that the results were more reliable and comparable and systematic error may also explain the variation. 
Table 2. Measures of association between POP concentration and anogenital distance measured in children in a linear regression model

\begin{tabular}{|c|c|c|c|c|c|}
\hline & \multirow{2}{*}{$\begin{array}{l}\text { Geometric mean } \\
(95 \% \mathrm{CI})\end{array}$} & \multicolumn{2}{|c|}{ Model 1} & \multicolumn{2}{|c|}{ Model 2} \\
\hline & & $\beta$ & $95 \% \mathrm{CI}$ & $\beta$ & $95 \% \mathrm{CI}$ \\
\hline \multicolumn{6}{|c|}{ Maternal serum } \\
\hline \multicolumn{6}{|c|}{$\mathrm{HCB}$} \\
\hline Male & $79.57(51.39,123.2)$ & -0.07 & $-0.49,0.34$ & 0.01 & $-0.43,0.45$ \\
\hline Female & $63.14(35.72,111.61)$ & -0.08 & $-0.48,0.30$ & -2.28 & $-0.05,0.05$ \\
\hline \multicolumn{6}{|l|}{ 4,4-DDD } \\
\hline Male & $1.41(0.78,2.53)$ & -0.36 & $-0.60,-0.12$ & -0.30 & $-0.62,0.01$ \\
\hline Female & $1.28(0.69,2.34)$ & -0.10 & $-0.59,0.39$ & -0.06 & $-0.63,0.50$ \\
\hline \multicolumn{6}{|l|}{ 2,4-DDD } \\
\hline Male & $0.76(0.67,0.86)$ & -1.19 & $-2.47,0.07$ & -0.92 & $-3.22,1.38$ \\
\hline Female & $0.75(0.70,0.80)$ & 1.51 & $-2.90,5.93$ & 3.75 & $-1.05,8.55$ \\
\hline \multicolumn{6}{|l|}{ PCB-28 } \\
\hline Male & $2.84(1.63,4.94)$ & -0.23 & $-0.57,0.10$ & -0.11 & $-0.61,0.37$ \\
\hline Female & $4.74(2.32,9.67)$ & -0.08 & $-0.39,0.23$ & -0.06 & $-0.42,0.29$ \\
\hline \multicolumn{6}{|l|}{ PCB-52 } \\
\hline Male & $1.54(1.36,1.75)$ & -1.19 & $-2.46,0.07$ & -0.92 & $-3.22,1.38$ \\
\hline Female & $1.53(1.44,1,63)$ & 1.51 & $-2.90,5.94$ & 3.75 & $-1.05,8.56$ \\
\hline \multicolumn{6}{|l|}{ PBDE-28 } \\
\hline Male & $0.16(0.13,0.21)$ & -0.38 & $-0.78,0.01$ & -0.24 & $-0.67,0.19$ \\
\hline Female & $0.23(0.15,0.35)$ & 0.04 & $-0.28,0.37$ & 0.01 & $-0.40,0.29$ \\
\hline \multicolumn{6}{|l|}{ PBDE-99 } \\
\hline Male & $0.39(0.26,0.58)$ & -0.31 & $-0.53,-0.09$ & -0.28 & $-0.51,-0.04$ \\
\hline Female & $0.90(0.50,1.65)$ & 0.04 & $-0.22,0.31$ & 0.04 & $-0.21,0.30$ \\
\hline \multicolumn{6}{|l|}{ PBDE-153 } \\
\hline Male & $1.54(1.36,1.75)$ & -0.41 & $-0.87,0.04$ & -0.61 & $-1.11,-0.11$ \\
\hline Female & $1.53(1.44,1,63)$ & 0.11 & $-0.20,0.41$ & 0.09 & $-0.20,0.40$ \\
\hline
\end{tabular}

Model 1, crude nonadjusted model; Model 2, model adjusted by height at 18 months. HCB, hexachlorobenzene; 2,4-DDD, 2,4-dichlorodiphenyldichloroethane; 4,4-DDD, 1,1-dichloro-2,2-bis(4-chlorophenyl)ethane; PCBs, polychlorinated biphenyls; PBDEs, polybrominated diphenyl ethers.

The distributions of multiple POPs between maternal serum and cord serum or placenta are generally correlated, suggesting maternal-to-fetus transfer [5]. Vizcaino et al. [33] have suggested an association between prenatal exposure to POPs and inadequate gestational weight gain. While few reports on the possible effects of POP exposure on fetal growth have been published to date, some evidence suggests that prenatal exposure to these compounds could be associated with disturbed hormone levels during pregnancy [34-36]. Prenatal exposure to PCBs has been related to lower birth weight, decreased thyroid function, and modification of the sex ratio at birth [37, 38]. In another study in the same population of the present work, it was pointed out that PBDEs may impair fetal growth in late pregnancy and reduce birth size [39].

The association of AGD with POPs in maternal serum may reflect the effect of prenatal exposure to POPs that act as androgens. This association could provide indirect evidence of postnatal changes in AGD in response to androgen activity. To date, epidemiological data on AGD changes resulting from prenatal exposure to androgens, estrogens, and EDCs are limited. Decreased AGD and genital defects have been reported in male infants whose mothers had been exposed prenatally to EDCs [17]. Another study [21] evaluated a reduced anal position index, defined as the ratio of AGD to the distance between the coccyx and the scrotum, and found reduced values in male infants whose mothers had high first-trimester blood levels of 1,1-dichloro-2,2-bis( $p$-chlorophenyl)ethylene, a metabolite of the pesticide DDT. In contrast, a study of 781 newborns in Chiapas, Mexico [20], did not find an association between exposure to the antiandrogen 1,1-dichloro-2,2-bis(p-chlorophenyl)ethylene and AGD [20]. 
In humans, there is also evidence supporting a relationship between non-POPs and a decrease in AGD. One literature review concluded that AGD in newborns may express the degree of intrauterine hormonal alteration following exposure to hormonal disruptors [40]. One observational study [17] of 134 newborn males linked exposure to phthalates to AGD. Another study [19] of 65 newborns compared maternal urinary phthalate levels with phthalate concentrations in amniotic fluid and degree of AGD, finding a positive correlation between amniotic and urinary phthalate levels. In a second work, Swan et al. [18] reported, in a cohort of 736 children at 31 months of age, inverse associations between first-trimester exposure to diethylhexyl phthalate and AGD in boys.

In females, only two studies have evaluated the exposure to non-POPs. Swan et al. [18] concluded that no phthalates metabolites were associated with AGD measure in girls. In contrast, Huang et al. [19] found a significantly negative correlation between amniotic fluid MBP (monobutyl phthalate) and AGD. As our study particularly showed, Torres-Sanchez et al. [21] did also not find an association between 1,1-dichloro-2,2-bis(p-chlorophenyl)ethylene and AGD.

Our study has limitations that should be recognized. The measurement of AGD has been made by two different pediatricians and it can lead to variability in the results even though they have been previously trained. The movement of the child while the pediatrician performs the physical exam can also influence the measure. We have determinations in maternal serum for persistent organic compounds but not for other compounds such as phthalates or PFAs which can affect the former measurements. Finally, divided by sexes, the numbers are quite small, which could limit the power; however, this study could serve as a basis for new studies including a larger sample size. One of the main strengths of the study is that we have been able to measure the concentration of different POPs in maternal blood, some of them forbidden nowadays, in order to check the effect they may have on the genital development over a population as vulnerable to changes as children. Another strength is that we represented the AGD stratified by sex and analyzed the results separately, paying attention to the female population because in the literature reviewed to date there are not many references which study this group in detail.

In summary, we found a negative association between AGD and exposure to PBDE-99 and PBDE-153 in males at 18 months of age, but no association with other POPs. We did not find any noteworthy relationship between
POPs and AGI in females. Our findings suggest that even at low levels of environmental exposure, POPs may affect genital development and result in reproductive tract alterations with potentially relevant health consequences in maturity. Large-sample longitudinal studies are warranted to confirm the association between POP exposure and AGD, as well as the long-term effects on health.

\section{Acknowledgment}

The authors would like to thank the participants and Hospital San Agustín in Avilés for their generous collaboration. We thank Edanz Group (www.edanzediting.com/ac) for editing a draft of this manuscript.

\section{Statement of Ethics}

The Ethics Research Committee of Asturias approved the research protocol, and all mothers provided written informed consent prior to inclusion.

\section{Disclosure Statement}

The authors declare no competing financial interest.

\section{Funding Sources}

This study was funded by grants from FIS-FEDER (PI04/2018, PI09/02311, and PI13/02429), Fundación Cajastur-Liberbank, and Universidad de Oviedo.

\begin{tabular}{|c|c|c|}
\hline References & 1 & $\begin{array}{l}\text { Vizcaino E, Grimalt JO, Lopez-Espinosa MJ, } \\
\text { Llop S, Rebagliato M, Ballester F. Maternal } \\
\text { origin and other determinants of cord serum } \\
\text { organochlorine compound concentrations in } \\
\text { infants from the general population. Environ } \\
\text { Sci Technol. } 2010 \text { Aug;44(16):6488-95. } \\
\text { SCOPS: Stockholm Convention on Persistent } \\
\text { Organic Pollutants (POPs) 2009;2017. Avail- } \\
\text { able from: http://chm.pops.int/TheConven- } \\
\text { tion/ThePOPs/AllPOPs/tabid/2509/Default. } \\
\text { aspx. } \\
\text { Carrizo D, Grimalt JO, Ribas-Fito N, Sunyer } \\
\text { J, Torrent M. Physical-chemical and maternal } \\
\text { determinants of the accumulation of organo- } \\
\text { chlorine compounds in four-year-old chil- } \\
\text { dren. Environ Sci Technol. 2006 Mar;40(5): } \\
\text { 1420-6. } \\
\text { Simonich SL, Hites RA: Global distribution of } \\
\text { persistent organochlorine compounds. Sci- } \\
\text { ence. } 1995 \text { Sep;269(5232):1851-4. }\end{array}$ \\
\hline
\end{tabular}

Horm Res Paediatr 2018;90:116-122 121 
5 Vizcaino E, Grimalt JO, Fernández-Somoano A, Tardon A. Transport of persistent organic pollutants across the human placenta. Environ Int. 2014 Apr;65:107-15.

6 McIntyre BS, Barlow NJ, Foster PM. Androgen-mediated development in male rat offspring exposed to flutamide in utero: permanence and correlation of early postnatal changes in anogenital distance and nipple retention with malformations in androgen-dependent tissues. Toxicol Sci. 2001 Aug;62(2): 236-49.

7 Wolf CJ, LeBlanc GA, Gray LE Jr. Interactive effects of vinclozolin and testosterone propionate on pregnancy and sexual differentiation of the male and female SD rat. Toxicol Sci. 2004 Mar;78(1):135-43.

8 WHO. Global assessment of the state-of-thescience of endocrine disruptors. Chapter 8: General conclusions and research Needs. 2002, pp. 131-2.

9 Diamanti-Kandarakis E, Bourguignon JP, Giudice LC, Hauser R, Prins GS, Soto AM, et al. Endocrine-disrupting chemicals: an Endocrine Society scientific statement. Endocr Rev. 2009 Jun;30(4):293-342.

10 Bartke A, Williams KI, Dalterio S. Effects of estrogens on testicular testosterone production in vitro. Biol Reprod. 1977 Dec;17(5): 645-9.

11 Sharpe RM, Skakkebaek NE. Are oestrogens involved in falling sperm counts and disorders of the male reproductive tract? Lancet. 1993 May;341(8857):1392-5.

12 Costa O, Lopez-Espinosa MJ, Vizcaino E, Murcia M, Iñiguez C, Navarrete-Muñoz EM, et al. Dietary and Household Sources of Prenatal Exposure to Polybrominated Diphenyl Ethers (PBDEs) in the INMA Birth Cohort (Spain). Environ Sci Technol. 2016 Jun; 50(11):5935-44.

13 Salazar-Martinez E, Romano-Riquer P, Yanez-Marquez E, Longnecker MP, Hernandez-Avila M. Anogenital distance in human male and female newborns: a descriptive, cross-sectional study. Environ Health. 2004 Sep;3(1):8.

14 Bowman CJ, Barlow NJ, Turner KJ, Wallace DG, Foster PM. Effects of in utero exposure to finasteride on androgen-dependent reproductive development in the male rat. Toxicol Sci. 2003 Aug;74(2):393-406.

15 Gallavan RH Jr, Holson JF, Stump DG, Knapp JF, Reynolds VL. Interpreting the toxicologic significance of alterations in anogenital distance: potential for confounding effects of progeny body weights. Reprod Toxicol. 1999 Sep-Oct;13(5):383-90.

16 Wolf C Jr, Lambright C, Mann P, Price M, Cooper RL, Ostby J, et al. Administration of potentially antiandrogenic pesticides (procymidone, linuron, iprodione, chlozolinate, $\mathrm{p}, \mathrm{p}^{\prime}$-DDE, and ketoconazole) and toxic substances (dibutyl- and diethylhexyl phthalate, PCB 169, and ethane dimethane sulphonate) during sexual differentiation produces diverse profiles of reproductive malformations in the male rat. Toxicol Ind Health. 1999 JanMar;15(1-2):94-118.

17 Swan SH, Main KM, Liu F, Stewart SL, Kruse RL, Calafat AM, et al.; Study for Future Families Research Team. Decrease in anogenital distance among male infants with prenatal phthalate exposure. Environ Health Perspect. 2005 Aug;113(8):1056-61.

18 Swan SH, Sathyanarayana S, Barrett ES, Janssen S, Liu F, Nguyen RH, et al.; TIDES Study Team. First trimester phthalate exposure and anogenital distance in newborns. Hum Reprod. 2015 Apr;30(4):963-72.

19 Huang PC, Kuo PL, Chou YY, Lin SJ, Lee CC. Association between prenatal exposure to phthalates and the health of newborns. Environ Int. 2009 Jan;35(1):14-20.

20 Longnecker MP, Gladen BC, Cupul-Uicab LA, Romano-Riquer SP, Weber JP, Chapin $\mathrm{RE}$, et al. In utero exposure to the antiandrogen 1,1-dichloro-2,2-bis(p-chlorophenyl) ethylene (DDE) in relation to anogenital distance in male newborns from Chiapas, México. Am J Epidemiol. 2007 May;165(9):101522.

21 Torres-Sanchez L, Zepeda M, Cebrián ME, Belkind-Gerson J, Garcia-Hernandez RM, Belkind-Valdovinos U, et al. Dichlorodiphenyldichloroethylene exposure during the first trimester of pregnancy alters the anal position in male infants. Ann N Y Acad Sci. 2008 Oct; 1140(1):155-62.

22 Guxens M, Ballester F, Espada M, Fernández MF, Grimalt JO, Ibarluzea J, et al.; INMA Project. Cohort Profile: the INMA-INfancia y Medio Ambiente-(Environment and Childhood) Project. Int J Epidemiol. 2012 Aug;41(4):930-40.

23 Vizcaino E, Arellano L, Fernandez P, Grimalt JO. Analysis of whole congener mixtures of polybromodiphenyl ethers by gas chromatography-mass spectrometry in both environmental and biological samples at femtogram levels. J Chromatogr A. 2009 Jun; 1216(25): 5045-51.

24 Grimalt JO, Carrizo D, Garí M, Font-Ribera L, Ribas-Fito N, Torrent M, et al. An evaluation of the sexual differences in the accumulation of organochlorine compounds in children at birth and at the age of 4 years. Environ Res. 2010 Apr;110(3):244-50.

25 Phillips DL, Pirkle JL, Burse VW, Bernert JT Jr, Henderson LO, Needham LL. Chlorinated hydrocarbon levels in human serum: effects of fasting and feeding. Arch Environ Contam Toxicol. 1989 Jul-Aug; 18(4):495-500.

26 Institute of Medicine (US) and National Research Council (US) Committee to Reexamine IOM Pregnancy Weight Guidelines; Rasmussen KM, Yaktine AL, editors. Weight Gain During Pregnancy: Reexamining the Guidelines. Washington (DC): National Academies Press (US); 2009. Available from: https://www.nap.edu/read/12584/chapter/1.

27 R Core Team. R. A Language and Environment for Statistical Computing. Vienna: R Foundation for Statistical Computing; 2014.
ISBN 3-900051-07-0. Available from: http:// www.R-project.org/.

28 Hsieh MH, Breyer BN, Eisenberg ML, Baskin LS. Associations among hypospadias, cryptorchidism, anogenital distance, and endocrine disruption. Curr Urol Rep. 2008 Mar; 9(2):137-42.

29 Romano-Riquer SP, Hernández-Avila $M$, Gladen BC, Cupul-Uicab LA, Longnecker MP. Reliability and determinants of anogenital distance and penis dimensions in male newborns from Chiapas, Mexico. Paediatr Perinat Epidemiol. 2007 May;21(3):219-28.

30 Thankamony A, Ong KK, Dunger DB, Acerini CL, Hughes IA. Anogenital distance from birth to 2 years: a population study. Environ Health Perspect. 2009 Nov;117(11):1786-90.

31 Phillip M, De Boer C, Pilpel D, Karplus M, Sofer S. Clitoral and penile sizes of full term newborns in two different ethnic groups. J Pediatr Endocrinol Metab. 1996 Mar-Apr;9(2): 175-9.

32 Callegari C, Everett S, Ross M, Brasel JA. Anogenital ratio: measure of fetal virilization in premature and full-term newborn infants. J Pediatr. 1987 Aug;111(2):240-3.

33 Vizcaino E, Grimalt JO, Glomstad B, Fernández-Somoano A, Tardón A. Gestational weight gain and exposure of newborns to persistent organic pollutants. Environ Health Perspect. 2014 Aug;122(8):873-9.

34 Chevrier J, Harley KG, Bradman A, Gharbi M, Sjödin A, Eskenazi B. Polybrominated diphenyl ether (PBDE) flame retardants and thyroid hormone during pregnancy. Environ Health Perspect. 2010 Oct;118(10):1444-9.

35 Lopez-Espinosa MJ, Vizcaino E, Murcia M, Llop S, Espada M, Seco V, et al. Association between thyroid hormone levels and 4,4'-DDE concentrations in pregnant women (Valencia, Spain). Environ Res. 2009 May;109(4):479-85.

36 Llop S, Murcia M, Alvarez-Pedrerol M, Grimalt JO, Santa-Marina L, Julvez J, et al. Association between exposure to organochlorine compounds and maternal thyroid status: role of the iodothyronine deiodinase 1 gene. Environ Int. 2017 Jul;104:83-90.

37 Álvarez-Pedrerol M, Ribas-Fitó N, Torrent M, Carrizo D, Grimalt JO, Sunyer J. Effects of PCBs, p, p'-DDT, p, p'-DDE, HCB and $\beta-\mathrm{HCH}$ on thyroid function in preschool children. Occup Environ Med. 2008 Jul;65(7):452-7.

38 Konishi K, Sasaki S, Kato S, Ban S, Washino $\mathrm{N}$, Kajiwara J, et al. Prenatal exposure to PCDDs/PCDFs and dioxin-like PCBs in relation to birth weight. Environ Res. 2009 Oct; 109(7):906-13.

39 Lopez-Espinosa MJ, Costa O, Vizcaino E, Murcia M, Fernandez-Somoano A, Iñiguez C, et al. Prenatal Exposure to Polybrominated Flame Retardants and Fetal Growth in the INMA Cohort (Spain). Environ Sci Technol. 2015 Aug;49(16):10108-16.

40 Agramunt S, Kogevinas M, Carreras R. [Anogenital distance in newborns: a sensitive marker of prenatal hormonal disruption]. Med Clin (Barc). 2011 Oct;137(10):459-63. 